Authors' Accepted Manuscript.

Published in: Post-Medieval Archaeology Vol. 50, Iss. 1 (2016), pp.148-158

DOI: $10.1080 / 00794236.2016 .1169488$

\title{
The contemporary in post-medieval archaeology
}

\author{
Laura McAtackney* and Sefryn Penrose ${ }^{\star \star}$
}

*Aarhus University, laura.mcatackney@gmail.com

** University College London, sefryn@gmail.com

SUMMARY: Contemporary archaeology is an emerging field of enquiry within the wider discipline associated with the questioning of temporal boundaries in what we study and why we engage with material remains of the recent past more generally. This article argues that contemporary archaeology should be broadly defined at this stage in its development and therefore can be located in Post-Medieval Archaeology through research that explicitly engages with what it is to conduct contemporary archaeology, but also through those implicitly considering how the past intrudes into the present. We believe that Post-Medieval Archaeology will continue to highlight archaeological studies of the contemporary into the future.

\section{DEFINING THE RECENT PAST}

The term 'contemporary archaeology' is often used interchangeably with the terms 'archaeology of the recent past', 'archaeology of the present' or 'archaeology of the contemporary past', or even as a broadening temporal extension of 'later historical archaeology', to designate archaeological engagements - to varying degrees and depths - with the material remains of the recent past. Recognizing that each of these titles poses subtle but potentially significant differences in meaning can make selecting a term that covers all possibilities and permeations problematic, if not impossible. For the sake of consistency and pragmatism, we will adopt the use of 'contemporary archaeology' as a broadly conceived framing term 
that is consistent with our definition of the breadth of the field and makes sense to the widest possible audience. For a more thorough treatment of defining the scope and range of 'contemporary archaeology', there are a number of sources, and the relatively new Journal of Contemporary Archaeology is undoubtedly a good place to start. ${ }^{2}$

However, one cannot so simply sidestep the issue of definitions. The number of definitions of 'contemporary archaeology' that have been offered in recent years reveals the subdiscipline as a vibrant, broad but sometimes scattered field, the emergence of which in some ways mirrors the earlier transition of 'historical archaeology' into mainstream archaeological consciousness and acceptability. That once-emerging field also experienced a period of angst regarding nomenclature, definitions and detailed justifications of what was 'archaeological' about particular approaches and studies. ${ }^{3}$ Contemporary archaeology as it presently stands (and as a 'new' subdiscipline it is constantly evolving, dividing and redefining itself) does not appear to be following proscriptive guidelines as to what it is to be a contemporary archaeologist or what a typical contemporary archaeology looks like. For influential writers such as Rodney Harrison and John Schofield, ${ }^{4}$ case studies are diverse, while definitions are vague and used to broaden rather than restrict those who may be included in the field. In essence, definitions allow the practitioner to define their work as contemporary archaeology without having to fulfil predetermined criteria. They define such archaeologies as almost limitless and indefinable in terms clearer than 'studies on material culture of the recent past'. For other theorists such as James Dixon, ${ }^{5}$ in contrast, there is an emphasis on examining the mindset of the archaeologist - not just what they are studying, but how and why they are studying it - which is crucial to the contemporaneity of their research. For the purposes of this article, we are not aiming definitively to assign one definition precedent over others. We allow for 'contemporary archaeology' to encompass archaeologies of the recent past, contemporary past or recent historical in nature, and in doing so attempt to take a holistic approach to the subject. We consider contemporary archaeology as broadly as possible and allow for those who self-identify as conducting research on the contemporary, as well as those who show elements of inspiration from contemporary archaeology, to be included in our explorations.

Defining contemporary archaeology as a subdiscipline is one issue; defining contemporary archaeology within the context of Post-Medieval Archaeology $(P M A)$ is another task entirely. Perhaps the most obvious point of departure for a review of contemporary archaeology within PMA, as part of this 50th-anniversary issue, is as recently as 2011 . We argue that the position piece of James Dixon (and response by Chris King), writing on the 
subject 'Is the present day post-medieval?', is central to understanding PMA's evolving engagement with contemporary archaeology. Just five years ago, Dixon stated without contradiction that, despite the Society for Post-Medieval Archaeology (SPMA) including archaeology up to the present day in its remit since 2006, this fundamental shift in perspective had not been mirrored in the contents of its journal. Dixon noted that only one full-length article that focused on the archaeological interpretation of materials dated post-1900 had been published in PMA at the time of writing. ${ }^{6}$ The article that Dixon was referencing, written by Linda Monckton on Bletchley Park, ${ }^{7}$ was generously conceived as contemporary in his argument, although its subject of Second World War intelligence is probably more in keeping with the aims of conflict archaeology, ${ }^{8}$ rather than any attempt to be explicitly contemporary. Although King disputed that this lack of publications reflected a lack of engagement with contemporary archaeology by the SPMA (indeed, he noted the involvement of many selfidentifying contemporary archaeologists at two SPMA conferences around that time), ${ }^{9}$ he did not argue that prior to 2011 there had been little engagement with the contemporary in the wider understandings of 'postmedieval' in PMA. This is an interesting aspect of King's response, for when one engages with the broadest interpretations of contemporary archaeology - as we have for the purposes of this article - there is an argument that the contemporary can be glimpsed in articles throughout the journal.

A positive interpretation of the lack of consensus regarding what is 'contemporary' about 'contemporary archaeology', and how we categorize articles within this moving moment, allows for articles that do not claim to be about the contemporary to reveal aspects of it. For example, there are aspects of the contemporary in articles throughout PMA that are almost definitely not written as self-conceived works of 'contemporary archaeology' by the authors, but rely on perspectives, theories and methodological approaches that do, however, stray into the realms of the study of the more recent past. Harold Mytum, for example, argues that the need for archaeologists to reflexively consider writing as a craft, which must simultaneously engage with the pasts we are trying to reconstruct and our contemporary means of communicating, focuses on the construction of knowledge in ways that tie in with contemporary archaeological interests. ${ }^{10}$

Elsewhere, Hugh Willmott and Alan Bryson's detailed examination of Monk Bretton Priory in South Yorkshire also reveals a long-term perspective with a place that is often considered only from its Golden Age as a functional religious building. ${ }^{11}$ Willmott and Bryson deliberately take a long-term perspective on the dissolution of the monasteries to show that there is a need to include more contemporary engagements with not only the remains of a distant past, but also our engagements with them. This fits 
with a frequently observed maxim within contemporary archaeology that the contemporary 'now-time' is multi-temporal and multi-scalar; all things exist within it. By examining Monk Bretton Priory to at least the mid-20th century, and by including substantial reflection on how amateur and professional archaeologists have affected the interpretation of such sites, there is a more contemporary relevance and reflexivity to this piece than one would normally associate with articles on the archaeology of the early modern period. Although it was undoubtedly not the explicit aim of Willmott and Bryson, the reflexive qualities of contemporary archaeology appear to have been an influence on the conceptions of the relationship between the deep past, the recent past and the present, making it an article that one could describe as having hints of the contemporary, if not the overt aspirations. This is not an unusual finding throughout the pages of $P M A$, and is mirrored in other archaeological arenas - most explicitly in industrial archaeology and in historical archaeology as practised in the USA, for example. ${ }^{12}$

Therefore, to consider the role of the contemporary on the occasion of the 50th-anniversary issue - in the past, present and future of PMA - one must use the 2011 articles by Dixon and King as watershed moments, but at the same time be careful to question their tacit agreement on a lack of the 'contemporary' in PMA. While many of the articles that have hints of the contemporary were not conceived as such, it is clear that their desire to create longer trajectories of the places they study and to be reflexive over their situatedness borrows from contemporary archaeologists' emphasis on a past-present continuum and a consciousness of our presentist bias. As well as fore-fronting this reservation, one must accept that Dixon's article reads as a rallying cry for broadly conceived contemporary archaeological outputs within the pages of PMA. Since Dixon's article, the number of notes and full-length articles that represent both traditional archaeological approaches to exploring materials from the moving moment of 'the recent past' and creative engagements with the idea of the archaeological present has increased in scale and scope. From Gabriel Moshenska's dissection of a ubiquitous contemporary material (a 'found' memory stick), ${ }^{13}$ to Paul Graves-Brown's exploration of globalization through the case study of the Encinal Terminal ${ }^{14}$ and Ceri Houlbrook's examination of the c. 2000-year history of coin-trees, ${ }^{15}$ PMA has increasingly become an accepted outlet for studies of the material culture of the recent past, if not necessarily the conceptually contemporary.

Some perspective: while this article notes that contemporary archaeology is represented more fully since Dixon's position paper of 2011, this is not to say that it has a dominant position within the journal. It is still rare to find more than one article of a contemporary subject or perspective — if even one - in any issue of the journal. Indeed, it may be said that the 
real, substantial change in the scope of the type of article published by PMA since 2011 is the move from a UK- and Irish-based geographical setting to a truly global representation. It is possible that this successful broadening in global reach has inadvertently detrimentally impacted on the representation of overtly contemporary pieces, as many of the new geographical areas of research are much more traditional in their sense of what archaeology is and how temporally close it is to the present. One could especially note that the greater inclusion of articles originating from central Europe and South America in a range, scope and frequency that are hitherto unknown for the journal ensures the methodological approaches, theoretical standpoints and temporal ranges are more traditional than innovative.

One could argue that the most appropriate perspective to take with regard to an increased emphasis on the contemporary in PMA is a qualitative one. This is especially the case as some truly groundbreaking studies in contemporary archaeology have been published through PMA, which raise not only the profile of contemporary archaeology, but also that of the journal itself. These include the intriguing methodological article on 'a contemporary homeless place', published by Gillian Crea et al. in 2014. ${ }^{16}$ This article follows a social justice imperative, which is a notable facet of some types of contemporary archaeology, but does so while maintaining a strong emphasis on utilizing traditional archaeological methodologies - in fact, more so than in most other contemporary archaeologies. Crea et al. follow an explicit engagement with using archaeological excavation techniques as they work alongside local homeless people as a deliberate form of 'social action'. ${ }^{17}$ Such an emphasis provides a contemporary mindset in keeping with the more precise definitions of what it is to do contemporary archaeology as delineated by Dixon. ${ }^{18}$ Indeed, the focus on using formal archaeological methodologies to excavate a decidedly contemporary site, with the stated aims including empowering the community of diggers, provides an insight into one difference that can be located between historical and contemporary archaeologies: the explicit engagement with social justice issues within the latter.

Robert Maxwell's 2012 article, 'After the car: navigating the archaeology of abandonment in Detroit, Michigan', ${ }^{19}$ also pushed archaeological boundaries within PMA, not just in its contemporary study of abandonment in Detroit, or in its advocacy in practice of Harrison's argument for archaeology as assembling/ reassembling beyond formal practices, ${ }^{20}$ but particularly in its use of film - published simultaneously online. That such challenging and innovative articles are submitted to and published within $P M A$, despite the lack of long-term precedent, and also the fact that the journal did not go ahead with a much-discussed name change in order to attract such publications, is telling. While one cannot claim that PMA is at the vanguard of contemporary archaeology, it is clearly acknowledged as 
an appropriate, welcoming and supportive environment to publish such work. This is in contrast to the very minimal engagement with contemporary aspects when Dixon and King were debating only five years ago. In order to contextualise how contemporary archaeology has developed and changed emphasis over a longer timescale, there is a need to move beyond PMA and examine other publications and organizations.

\section{CONTEMPORARY ARCHAEOLOGY BEYOND PMA}

Writing recently in Industrial Archaeology Review, Paul Belford makes a coherent argument for a consolidated mainstreaming of what he calls 'twentieth-century archaeology' in order to ensure its relevance out of the 'academic bubble' and away from a perceived niche radicalism and into the public arena. ${ }^{21}$ Belford argues correctly that there has been no distinction between archaeology of the very recent past and industrial or historical archaeology in professional (i.e. outside academia) excavations for some time, as long as those recent layers are in context. Indeed, given Belford's discussion, it can be argued that the decision of the SPMA in 2006 to include the 'present day' merely reflected an understanding which had long existed in practice that the separation of periods was artificial. This is an enduring question within contemporary archaeology: is it different from any other period? For Belford, the profusion of data that we have for the recent past, and the fact that we have the 'voices' of those who lived it and live it, including ourselves, makes our use of formal archaeological methods largely irrelevant. ${ }^{22}$ While some of the most-cited contemporary archaeology projects that have sought to employ those formal methodological practices - the University of Bristol's van project, for example - have found themselves the subject of criticism, ${ }^{23}$ others have been lauded for their social activism or public relevance. ${ }^{24}$ But the emphasis on this engagement with the material of the recent past using methodologies that are familiar to archaeologists of all periods (for example, excavation or standardized recording practices) is not the defining praxis of contemporary archaeology.

Influenced by earlier modern material culture studies in anthropology, ${ }^{25}$ contemporary archaeology has emerged in a number of manifestations, but probably most memorably as a critical engagement with the material remnants and social phenomena of late modern societies, be that through manifestations of conflict or more mundane phenomena. ${ }^{26}$ Spatially, it recognizes the transitory and fluid state of space and place. ${ }^{27}$ Temporally, its focus is continuously shifting: occurring in the moving moment of the recent past; $^{28}$ engaging with the here and now as it slips away; 
encompassing the past and simultaneously the promises of the future. Materially, the physical traces of the past in the present are viewed diachronically as palimpsests (assemblages of layered, overlapping histories), ${ }^{29}$ as well as discrete and often mundane entities. In many ways, contemporary archaeology in praxis is a burgeoning, emergent specialization which incorporates transdisciplinary perspectives and methodologies that often shy away from the traditions of excavation and stratigraphy, instead preferring to borrow from history, geography, art, future studies and urban studies to best interpret the social, and often political, implications of the materiality of contemporary life. Instead of focusing on being methodologically 'archaeological', contemporary archaeologies often explicitly aim to locate the materializations of often unconsidered, forgotten, obfuscated or hidden aspects of the world around us, or at least familiar to us. In doing so, the aim of many contemporary archaeologies is to allow us to view global processes through the lens of local expressions, rather than being sidetracked by ensuring that we are 'being' archaeological in doing so.

Contemporary archaeology's interdisciplinarity - even within the field (it after all has ancestors in industrial, conflict, historical, ethno- and prehistoric archaeology, and is heavily influenced by anthropology, social studies and cultural geography) - is also what differentiates it from those antecedents. Described as a 'perspective', ${ }^{30}$ a 'way of seeing', 31 and 'mediation of the past as a creative engagement with the present and future', ${ }^{32}$ there does appear to be 'an imaginary' and imagination involved in viewing the contemporary from an archaeological standpoint. Those working with the contemporary past have in many cases moved away from what Harrison calls 'the trope of archaeology-as-excavation', ${ }^{33}$ and contemporary archaeology has instead become a lens with which we do what all archaeologists do: the work of interpretation.

As developed through annual meetings such as Contemporary and Historical Archaeology in Theory (CHAT, which was inaugurated at the University of Bristol in 2003 in a conference organized by Dan Hicks and Angela Piccini) and individual conferences, workshops and publications, contemporary archaeology has the potential to be all things to all comers, but at times can appear to be inconsequential, self-referential and even insular. CHAT, in particular, has been an acknowledged cornerstone of contemporary archaeology in the UK since the creation of this now annual conference over a decade ago, and has been the place where some of the most widely known and best-respected, as well as experimental and controversial, research has been presented. CHAT originated from, and continues to attract, those who have temporarily strayed or permanently migrated from more traditional historical archaeologies and, as such, there 
is a strong crossover with the SPMA. Some of the founding and existing committee members of CHAT have been committee members of the SPMA, including Eleanor Conlin Casella, James Dixon, James Symonds, Laura McAtackney, Sarah May and Hilary Orange. However, CHAT has definitely, if incrementally, moved from a fairly traditional emphasis on a broad conception of historical archaeology, not dissimilar to the SPMA, to being viewed as a vehicle for the 'contemporary' rather than 'historical'. As such, CHAT's role in the development of contemporary archaeology is widely acknowledged in ways that the SPMA's is not, despite the interconnected nature of both organizations.

This has not been without criticism. Some critics accuse the CHAT gatherings of being exclusionary, having an overemphasis on the 'contemporary' and downgrading the 'historical', and maintain that CHAT as a domain has become dominated by highly theoretical academics with no relevance to archaeology as practised. ${ }^{34}$ As current serving committee members of CHAT, we would like to argue that it is difficult to uphold such criticisms of the conferences as a collective, as a self-defining principle of CHAT is the relative hands-off approach its committee takes towards its conferences. While the CHAT committee is in place to guide, lightly direct and select conference venues, there is a significant degree of freedom given to the changing annual hosts to determine and direct the nature and form of the conference. Although this lack of central direction appears to have been forgotten or is unknown in some critiques, it is clear when one examines the themes and presentations at CHAT conferences over a number of years that the contemporary and the historical often live side by side. Rather than being obsessed with the contemporary, CHAT is a place to question archaeological and heritage orthodoxies, and it is perhaps this very questioning that is being critiqued as being a facet of the 'contemporary'. CHAT's relatively stable continuance is built around an annual conference that alternates between general and specific themes annually - for example, the broadly themed 'Together' conference, hosted by the University of Sheffield in 2015 after Richard Sennett's work of the same name, ${ }^{35}$ which was interpreted widely, from collaborative working to public engagement, and had a wide temporal emphasis, and the more specific 'Dark Modernities' conference, hosted by Pilsen in 2014, which focused almost exclusively on archaeologies of totalitarianism in 20thcentury Europe. ${ }^{36}$ So, for every tightly themed and focused conference that is critiqued for emphasizing the contemporary, there are at least equal numbers that have aimed to appeal more widely, with some even tailored to the more traditional and historical archaeological audience. ${ }^{37}$

A notable current at CHAT conferences is that these gatherings increasingly attract the participation of non-archaeological researchers and 
practitioners who are interested in the potentialities of contemporary archaeology and who share its thematic interests; performance artists, historians, geographers, photographers, real estate studies researchers and film-makers enjoy the relative freedom and laissez-faire ethos of the conference to present work that would not fit within more conventional formats. Conversely, practising archaeologists within development-led archaeology have also found it an appealing place to present their more experimental or interdisciplinary work. ${ }^{38}$ Criticisms aside, CHAT remains the only annual conference for contemporary archaeologists to transmit their work, and its annual diverse output is perhaps the key indicator for the diversity of the field. Despite the almost carnivalesque atmosphere of some CHAT gatherings, this does not fully represent the breadth and even darkness of much contemporary archaeology, and we argue that there is a need for greater engagement with the nuances of researching the contemporary by organizations such as the SPMA. ${ }^{39}$

The contemporary archaeological output in $P M A$ is largely restricted to North American and British works that are scattered at a rate of not more than one or two articles per issue. How does this compare to like-minded international peer-reviewed journals? If one leaves aside the new Journal of Contemporary Archaeology, which is the only peer-reviewed journal directly focused on contemporary archaeology, and examines the contents of comparative journals, it is clear that while there is an increasing interest in contemporary archaeology, the rate of coverage is similar, with few extensions of geographical range.

Historical Archaeology, the journal of the US-based Society for Historical Archaeology, has had a similar hit rate of around one contemporaryfocused article per issue since $c$. 2011. The contemporary nature of the articles we consider here is often historical archaeological case studies that extend to the recent past, rather than the contemporary being the sole focus. Historical Archaeology includes a wider geographical range, with a historical consideration of mining in Bolivia that extends to the recent past, for example, being covered. ${ }^{40}$ More general international journals such as the Norwegian Archaeological Review ${ }^{41}$ and the Journal of Social Archaeology ${ }^{42}$ have likewise shown a greater openness to topics and treatment situated in, and inspired by, the contemporary since c. 2010. Likewise, the International Journal of Historical Archaeology (IJHA) has featured sporadic British and North American articles that cover, or at least reach, the contemporary. ${ }^{43}$ Perhaps we can detect there, too, a more deliberate attempt at including contemporary archaeology since 2011 through imaginative and cutting-edge engagements with things, as well as people, and the emergence of contemporary capitalism. In particular, a 2012 special issue edited by Gavin Lucas, Later Historical Archaeology in Iceland: a Review, ${ }^{44}$ included Póra Pétursdóttir's important work on non- 
human agency and sites of ruination, ${ }^{45}$ as well as Gísli Pálsson's engagement with the ruins of post-crash development projects. ${ }^{46}$ While we see a strong contemporary archaeology strain that works with ruin, we also see the strength of post-structural theory incorporated in sophisticated understandings of the flotsam and jetsam of contemporary capitalism.

Also working with ruins of a sort, but this time using public engagement as an important component of site interpretation, Casella's 2012 IJHA article on the Alderley Sandhills Project excavation of the Hagg cottages illustrated a facet of contemporary archaeology that is at once fascinating, energizing and extremely difficult: how we work with the living. ${ }^{47}$ That project's use of oral testimony is illustrative of techniques that are already widespread in, for example, industrial archaeology, but extends into the mundane, the everyday: the way that ordinary lives have been lived. This inclusion of the living has already been mentioned in relation to the work of Crea et al. with the homeless of Bristol, ${ }^{48}$ and is a noticeable facet of other contemporary archaeology work, including McAtackney's long-standing project involving people imprisoned, housed or impacted by Long Kesh/Maze prison in Northern Ireland. ${ }^{49}$ Comparison with North American journal output also throws up interesting parallels: Larry Zimmerman, Courtney Singleton and Jessica Welch's 2010 article in World Archaeology on the contemporary material culture of homelessness has strong resonances with Rachael Kiddey's work on homelessness in the UK, ${ }^{50}$ and Myers' article in the IJHA on the van project indicates the close links between practitioners and their emergence from particular loci. ${ }^{51}$ At its most biting, contemporary archaeology is a politically engaged cultural critique and practice that can be unsettling in its recognition of the contrasts and consequences of past decisions with regard to present-day inequality; but equally it can allow us to intricately explore the materializations of the mundane and everyday. It can be a creative practice, ${ }^{52}$ which challenges practitioners to deal with raw emotion, nostalgia, personal memories and imagination, which are frequently lost in our distancing gaze of 'older' archaeologies. Contemporary archaeological projects often consider marginalized groups and the effects of contemporary society on people, material culture and place. $^{53}$ Published projects include critical engagements with homelessness, ${ }^{54}$ imprisonment, ${ }^{55}$ mass disaster, ${ }^{56}$ urban renewal, ${ }^{57}$ ruins, ${ }^{58}$ and deindustrialization. ${ }^{59}$ They can also be seemingly more light-hearted, offering canny and insightful critiques of the misleadingly mundane world of popular culture and the everyday, ${ }^{60}$ as well as foregrounding both nuanced and explicit understandings of memory and use of the past as an artefact and/or tool of the present. ${ }^{61}$ The intersection of contemporary archaeology with public memory, heritage, activism and recently lived experiences often results in politically engaged archaeologies, as the temporal proximity prevents complete detachment between 
researchers, their subject matter and associated contexts. ${ }^{62}$ At an epistemological level, contemporary archaeological study can serve as a critique of the ways in which archaeological knowledge is produced, in some cases contributing to transformative processes both within and beyond the discipline. ${ }^{63}$ Contemporary archaeology has the potential to be both global and local - about the structures of power and the lived experiences of individuals; the solid and the ephemeral; the political and the social. It may also be none of these things; such is its mercurial nature and our current standpoint, at the cusp of what it may or may not be.

\section{CONTEMPORARY ARCHAEOLOGY AND THE FUTURE}

King, in his response to Dixon, makes a case for contemporary archaeology to step back from its absorption in the immediate. ${ }^{64}$ Perhaps there is a point to be made here: the much-repeated maxim of making the familiar unfamiliar, $^{65}$ and the unfolding potentials of autoarchaeology, ${ }^{66}$ alongside the strong, often deliberately unbalanced social activism of much contemporary archaeology, has left a considerable hole in how we engage with the contemporaneity of our discipline. While there is certainly an argument to be made for the still-emergent position of contemporary archaeology to excuse this - there are not enough of us, and there is not enough funding to address all those issues that critics of the subdiscipline like to direct at it - and while the distancing that King advocates is not always possible or indeed desirable, there is something to be said for work that is not so partisan. There is room for understanding contemporary archaeology not as a millennial moment of endness, as some works seem to catastrophize it. Further, our position in this moment of change, rather than standing at the edge of the trench and looking in on that sealed and past moment of change, remains an archaeological one. We retain the same basic set of skills regarding understandings of the material as archaeologists of all periods, and the ability to apply those understandings and knowledge sets to complex phenomena. Matt Edgeworth's work on the challenges of the large and small, ${ }^{67}$ Graves-Brown's introduction of notions of inevitable loss into his work on the Encinal Terminal, ${ }^{68}$ Piccini's work on the presence of media in our lives, ${ }^{69}$ and Sara Perry and Colleen Morgan's work on the Media Archaeology Drive Project (MAD-P), 'to enunciate a formal procedure for the excavation of media objects', ${ }^{70}$ all illustrate the possibilities for archaeological engagements with these complexities, with the unique and extreme things of the Anthropocene, ubiquitous and pressing as the present moves on.

As contemporary archaeology remains at that moving moment that links studies traditionally rooted in the past, on the cusp of the future, we must 
also examine contemporary archaeology as a discipline that is increasingly centring its attention on the future. Understanding that disciplines largely focused on the past can be useful in determining not only the present, but also the future, is not a new concept, but the increasing interest in the materiality of future - or anticipation - studies is a noticeable current within contemporary archaeology that has not been translated to PMA articles. We might see London's Olympic year as a significant moment here, with the creation of the Olympic Park proving fertile ground for archaeologists to explore their own uneasy relationship with development and a landscape in the process of staged transition with a very specific future determined. ${ }^{71}$ More generally, the location of a number of contemporary archaeologists within teams working in planning and development has further pushed these engagements with futures. ${ }^{72}$ 'Assembling Alternative Futures for Heritage', for example, is an Arts and Humanities Research Council large-grant-funded interdisciplinary investigation into how heritage is constituted for an uncertain future, and indicates the potential of an interest in archaeological approaches to futuremaking practices. ${ }^{73}$ Contemporary archaeologists are among those who are most cogently engaged in these projects. Undoubtedly, those working on periods closest to the present - and, by logical extension, the future have been most concerned with the applicability of exploring the pastpresent-future continuum, and increasingly these studies are gaining interest and academic currency. One can only imagine that long-term projects with published and widely disseminated results on contemporary archaeologies of the future will increasingly come forth, and we remain hopeful that this includes more thought-provoking and groundbreaking work in the pages of $P M A$.

\section{CONCLUSIONS}

Contemporary archaeology is a relative newcomer to the wider archaeological discipline. Its output has been diverse but sometimes siloed. Those articles published in PMA over the years have tended towards a fairly formal understanding of archaeology, seeing archaeologies of the contemporary as a set of formal archaeological practices rather than a Holtorfian perspectivized view. The arrival of the Journal of Contemporary Archaeology in 2014 has now given contemporary archaeology a 'natural' home in print, and perhaps will absorb more of its cutting-edge contributions, but there is a need to recognize the growing importance, richness and depth of contemporary archaeology at a time when artificial impositions of cut-off dates are becoming less of a concern to a broader 
base of archaeologists. With the changing of the remit of PMA in 2006, the journal signalled its openness to diversity and, in particular, to works in contemporary archaeology practice to be included in its pages. This desire to engage with contemporary archaeology should therefore ensure the journal's continuing success as a home for those researching the contemporary in archaeology, particularly those undertaking multi-period and even multi-platform work. It is tempting, then, to suggest that just as current contemporary archaeology looks to the future, so too should this review of $P M A$ 's engagement with it.

\section{NOTES}

1 Buchli \& Lucas 2001; McAtackney et al. 2007; Olivier 2001; Harrison \& Schofield 2009; 2010.

2 See González-Ruibal et al. 2014.

3 See Tarlow \& West 1999; Funari et al. 1999; Hall \& Silliman 2006.

4 Harrison \& Schofield 2010.

5 Dixon 2011.

6 Dixon 2011.

7 Monckton 2006.

8 See Ferguson \& Scott, this issue.

$9 \quad$ King 2011, 324.

10 Mytum 2010.

11 Willmott \& Bryson 2013.

12 Belford 2014 and, for example, Webster 1999; Tzortzopoulou-Gregory 2010; Mullins \& Jones 2011.

13 Moshenska 2014.

14 Graves-Brown 2013.

15 Houlbrook 2015.

16 Crea et al. 2014.

17 Crea et al. 2014, 147.

18 Dixon 2011.

19 Maxwell 2012.

20 Harrison 2011, 141.

21 Belford 2014.

22 Belford 2014.

23 Bailey et al. 2009.

24 See Zimmerman et al. 2010.

25 See Gould \& Schiffer 1981; Rathje 1979; Graves-Brown 2000; Buchli \& Lucas 2001. 
González-Ruibal et al. 2014; Harrison 2011; Harrison \& Schofield 2010; Graves-Brown et al. 2013.

27 Hicks et al. 2007; Olsen et al. 2012; Pearson \& Shanks 2001.

28 Witmore 2012.

29 Harrison 2011.

30 Holtorf 2005, 15.

31 Penrose 2007, 13.

32 Harrison 2011, 160.

33 Harrison 2011, 143.

34 See King 2011; Belford 2014.

35 Sennett 2013.

36 In particular, given the geographical bias of contemporary archaeology, which most frequently concerns itself with Europe and the Americas, we would like to note the startling and imaginative contributions to that conference, and to the subfield in general, of Leila Papoli Yazdi. Her body of work concerns Iran and is consistently challenging and thought-provoking in its content and originality - see, for example, DezhamKhooy \& Yazdi 2010; Yazdi \& DezhamKhooy 2014.

37 Including CHAT Boston 2007 and CHAT Oxford 2009.

38 For example, Cambridge Archaeological Unit's work at the Robert Sayle department store, Cambridge (Cessford 2013), and the Museum of London Archaeology's (MOLA's) work undertaken during the re(construction) of the London Overground East London line (Dwyer 2011).

39 Although Pilsen in 2014, with its theme of 'Dark Modernities', was certainly grave in its subject matter.

40 See van Buren \& Weaver 2012, but also includes arguing for better, archaeologically based knowledge of Baltimore's historical past in contemporary planning issues by Shackel \& Gadsby 2011.

41 Graves-Brown 2011; Rasmussen 2014 and discussants.

42 McAtackney 2011; Ryzewski 2015.

43 For example, Myers 2011; Tzortzopoulou-Gregory 2010; Webster 1999; Pearson \& Mullins 1999.

44 Lucas 2012.

45 Pétursdóttir 2012.

46 Pálsson 2012.

47 Casella 2012.

48 Crea et al. 2014.

49 Including McAtackney 2014.

50 Zimmerman et al. 2010; Kiddey \& Schofield 2011.

51 Myers 2011.

52 Buchli \& Lucas 2001. 
53 Shanks 2004; González-Ruibal 2006.

54 Zimmerman et al. 2010.

55 McAtackney 2014.

56 Crossland 2002.

57 Mullins 2006.

58 Pétursdóttir \& Olsen 2014.

59 Orange 2014.

60 Holtorf 2007.

61 For example, Penrose 2010; Piccini 1999; Renshaw 2011.

62 Harrison \& Schofield 2009; Harrison 2015.

63 Including Edgeworth 2013; Witmore 2012.

64 King 2011.

65 For example, Graves-Brown 2000; Buchli \& Lucas 2001.

66 Harrison \& Schofield 2009.

67 Edgeworth 2013.

68 Graves-Brown 2013.

69 Piccini 2013; forthcoming.

70 Morgan \& Perry 2015, 96.

71 See, for example, Gardner forthcoming; Penrose 2012; Piccini 2013; forthcoming. Also Emma Dwyer's 'Art and Archaeology on an Olympian Scale', a guided walk at CHAT 2009.

72 For example, James Dixon's research work on non-completion.

73 The Arts and Humanities Research Council in the UK provided a significant grant to Harrison (Principal Investigator) et al. in 2014 to explore studies on the future through heritage - and, often, archaeology - perspectives.

\section{ORCID}

Penrose Sefryn http://orcid.org/0000-0002-4751-1348 


\section{REFERENCES}

Bailey, G. et al. 2009, 'Transit, transition: excavating J641 vUJ', Camb. Archaeol. J. 19:1, 1-28.

Belford, P. 2014, 'Contemporary and recent archaeology in practice', Ind. Archaeol. Rev. 36:1, 3-14.

Buchli, V. \& Lucas, G. (eds) 2001, Archaeologies of the Contemporary Past, London: Routledge.

Casella, E.C. 2012, "'That's just a family thing, you know": memory, community kinship, and social belonging in the Hagg cottages of Cheshire, north-west England', Int. J. Hist. Archaeol. 16:2, 284-99.

Cessford, C. 2013, 'Life in a "cathedral of consumption": corporate and personal material culture recovered from a cellar at the Robert Sayle department store in Cambridge, England, ca. 1913-21', Int. J. Hist. Archaeol. 16:4, 784-808.

Crea, G. et al. 2014, 'Turbo Island: excavating a contemporary homeless place', Post-Medieval Archaeol. 48:1, 133-50.

Crossland, Z. 2002, 'Violent spaces: conflict over the reappearance of Argentina's disappeared', in Schofield, Beck \& Johnson 2002, 115-31.

DezhamKhooy, M. \& Yazdi, L.P. 2010, 'The archaeology of last night ... what happened in Bam (Iran) on 25-6 December 2003', World Archaeol. 42:3, 341-54.

Dixon, J. 2011, 'Is the present day post-medieval?', Post-Medieval Archaeol. 45:2, 313-21.

Dwyer, E. 2011, The Impact of the Railways in the East End 1835-2010: Historical Archaeology from the London Overground East London Line, MOLA Monogr. 52.

Edgeworth, M. 2013, 'Scale', in Graves-Brown, Harrison \& Piccini 2013, 379-91.

Fortenberry, B. \& McAtackney, L. (eds) 2012, Modern Materials: Papers from CHAT Oxford (2009), Oxford: Archaeopress.

Funari, P., Hall, M. \& Jones, S. (eds) 1999, Historical Archaeology, London: Routledge.

Gadsby, D.A., \& R. C. Chidester. 'Heritage and "those people": representing working-class interests through Hampden's archaeology', Hist. Archaeol. 45:1, 101-113.

Gardner, J. forthcoming, 'Recurring dreams/nightmares: mega events and traces of uncertain futures', Archaeol. Dialogues.

González-Ruibal, A. 2006, 'The dream of reason: an archaeology of the failures of modernity in Ethiopia', J. Soc. Archaeol. 6:2, 175-201. 
González-Ruibal, A. et al. 2014, 'Archaeologies of the contemporary past: an interview with victor Buchli and Gavin Lucas', J. Contemp. Archaeol. $1: 2,265-76$.

Gould, R. \& Schiffer, M. (eds) 1981, Modern Material Culture: the Archaeology of Us, New York: Academic Press.

Graves-Brown, P. (ed.) 2000, Matter, Materiality and Modern Culture, London: Routledge.

Graves-Brown, P. 2011, 'Touching from a distance: alienation, abjection, estrangement and archaeology', Nor. Archaeol. Rev. 44:2, 131-44.

Graves-Brown, P. 2013, 'The box and the Encinal Terminal: an archaeology of globalization', Post-Medieval Archaeol. 47:1, 253-60.

Graves-Brown, P., Harrison, R. \& Piccini, A. (eds) 2013, The Oxford Handbook of the Archaeology of the Contemporary World, Oxford: University Press.

Hall, M. \& Silliman, S. (eds) 2006, Historical Archaeology, Oxford: Blackwell.

Harrison, R. \& Schofield, J. 2009, 'Archaeo-ethnography, auto-archaeology: introducing archaeologies of the contemporary past', Archaeologies 5:2, 185-209.

Harrison, R. \& Schofield, J. 2010, After Modernity: Archaeological Approaches to the Contemporary Past, Oxford: University Press.

Harrison, R. 2011, 'Surface assemblages: towards an archaeology in and of the present', Archaeol. Dialogues 18:2, 141-61.

Harrison, R. 2015, 'Beyond "natural" and "cultural" heritage: toward an ontological politics of heritage in the age of Anthropocene', Herit. Soc. 8:1, 24-42.

Hicks, D., McAtackney, L. \& Fairclough, G. (eds) 2007, Envisioning Landscape Situations and Standpoints in Archaeology and Heritage, Walnut Creek: Left Coast Press.

Holtorf, C. 2005, From Stonehenge to Las Vegas: Archaeology as Popular Culture, Lanham: AltaMira Press.

Holtorf, C. 2007, 'Can you hear me at the back? Archaeology, communication and society', Europ. J. Archaeol. 10:2-3, 149-65.

Houlbrook, C. 2015, 'Small change: economic and coin-trees in Britain and Ireland', Post-Medieval Archaeol. 49:1, 114-30.

Kiddey, R. \& Schofield, J. 2011, 'Embrace the margins: adventures in archaeology and homelessness', Public Archaeol. 10:1, 4-22.

King, C. 2011, 'Is the present day post-medieval? A response', PostMedieval Archaeol. 45:2, 322-4.

Lucas, G. (ed.) 2012, Later Historical Archaeology in Iceland: A Review, Int. J. Hist. Archaeol., 16:3. 
Maxwell, R. 2012, 'After the car: navigating the archaeology of abandonment in Detroit, Michigan', Post-Medieval Archaeol. 46:2, 34752.

McAtackney, L. 2011, 'Peace maintenance and political messages: the significance of walls during and after the Northern Irish Troubles', J. Soc. Archaeol. 11:1, 77-98.

McAtackney, L. 2014, An Archaeology of the Troubles: the Dark Heritage of Long Kesh/Maze Prison, Northern Ireland, Oxford: University Press.

McAtackney, L., Palus, M. \& Piccini, A. (eds) 2007, Contemporary and Historical Archaeology in Theory: Papers from the 2003 and 2004 CHAT Conferences, Brit. Archaeol. Rep. S1677.

Merriman, N. (ed.) 1999, Making Early Histories in Museums, Leicester: University Press.

Monckton, L. 2006, 'Bletchley Park, Buckinghamshire: the architecture of the Government Code and Cypher School', Post-Medieval Archaeol. 40:2, 291-300.

Moshenska, G. 2014, 'The archaeology of (flash) memory', Post-Medieval Archaeol. 48:1, 255-9.

Mullins, P. \& Jones, L.C. 2011, 'Archaeologies of race and urban poverty: the politics of slumming, engagement, and the color line', Hist. Archaeol. 45:1, 33-50.

Mullins, P. 2006, 'Racializing the commonplace landscape: an archaeology of urban renewal along the color line', World Archaeol. 38:1, 60-71.

Myers, A. 2011, 'Contemporary archaeology in transit: the artifacts of a 1991 van', Int. J. Hist. Archaeol. 15:1, 138-61.

Mytum, H. 2010, 'Ways of writing in post-medieval and historical archaeology: introducing biography', Post-Medieval Archaeol. 44:2, 237-54.

Olivier, L. 2001, 'The archaeology of the contemporary past', in Buchli \& Lucas 2001, 175-88.

Olsen, B. et al. 2012, Archaeology: the Discipline of Things, Berkeley: University of California Press.

Orange, H. 2014, Reanimating Industrial Spaces: Conducting Memory Work in Post-Industrial Societies, Walnut Creek: Left Coast Press.

Pálsson, G. 2012, 'These are not old ruins: a heritage of the Hrun', Int. J. Hist. Archaeol. 16:3, 559-76.

Pearson, M. \& Mullins, P. 1999, 'Domesticating Barbie: an archaeology of Barbie material culture and domestic ideology', Int. J. Hist. Archaeol. 3:4, 225-59.

Pearson, M. \& Shanks, M. 2001, Theatre/Archaeology, London: Routledge.

Penrose, S. 2007, Images of Change: an Archaeology of England's Contemporary Landscape, Swindon: English Heritage. 
Penrose, S. 2010, 'Recording transition in post-industrial England: a future perfect view of Oxford's Motopolis', Archaeologies 6:1, 167-80.

Penrose, S. 2012, 'London 1948: the sites and after-lives of the austerity Olympics', World Archaeol. 44:2, 306-25.

Perry, S. \& Morgan, C. 2015, 'Materializing media archaeologies: the MADP hard drive excavation', J. Contemp. Archaeol. 2:1, 94-104.

Pétursdóttir, D. \& Olsen, B. 2014, Ruin Memories: Materiality, Aesthetics and the Archaeology of the Recent Past, London: Routledge.

Pétursdóttir, P. 2012, 'Small things forgotten now included, or what else do things deserve?' Int. J. Hist. Archaeol. 16:3, 577-603.

Piccini, A.A. 1999, 'Wargames and Wendy houses: open-air reconstructions of prehistoric life', in Merriman 1999, 151-72.

Piccini, A.A. 2013, 'Olympic City screens: media, matter, and making place', in Graves-Brown, Harrison \& Piccini 2013, 610-26.

Piccini, A.A. forthcoming, 'Media archaeologies of the Olympic City', Public.

Rasmussen, J.M. 2014, 'Reply to comments from Suzie Thomas, Martin Mesicek, Raimund Karl, Mads Ravn, Maria Lingström', Nor. Archaeol. Rev. 47:2, 212-17.

Rathje, W. 1979, 'Modern material culture studies', Adv. Archaeol. Method Theory 2, 1-37.

Renshaw, L. 2011, Exhuming Loss: Memory, Materiality and Mass Graves of the Spanish Civil War, Walnut Creek: Left Coast Press.

Ryzewski, K. 2015, "No home for the "ordinary gamut": a historical archaeology of community displacement and the creation of Detroit, City Beautiful', J. Soc. Archaeol. 15:3, 408-31.

Schofield, J., Beck, C. \& Johnson, W.G. (eds) 2002, Matériel Culture: the Archaeology of Twentieth Century Conflict, London: Routledge.

Sennett, R. 2013, Together, London: Penguin.

Shackel, P. 2011, 'Pursuing heritage; engaging communities' Hist. Archaeol. 45:1, 1-9.

Shackel, P.A. \& Gadsby, D. (eds) 2011, 'Archaeologies of engagement, representation, and identity', Hist. Archaeol. 45:1.

Shanks, M. 2004, 'Three rooms: archaeology and performance', J. Soc. Archaeol. 4:2, 147-80.

Tarlow, S. \& West, S. (eds) 1999, The Familiar Past? Archaeologies of Britain from 1550, London: Routledge.

Tzortzopoulou-Gregory, L. 2010, 'Remembering and forgetting: the relationship between memory and the abandonment of graves in nineteenth- and twentieth-century Greek cemeteries', Int. J. Hist. Archaeol. 14:2, 285-301. 
van Buren, M. \& Weaver, B.J. 2012, 'Contours of labor and history: a diachronic perspective on Andean mineral production and the making of landscapes in Porco, Bolivia', Hist. Archaeol. 46:3, 79-101.

Webster, J. 1999, 'Resisting traditions: ceramics, identity, and consumer choice in the Outer Hebrides from 1800 to the present', Int. J. Hist. Archaeol. 3:1, 53-73.

Willmott, H. \& Bryson, A. 2013, 'Changing to suit the times: a postDissolution history of Monk Bretton Priory, South Yorkshire', PostMedieval Archaeol. 47:1, 136-63.

Witmore, C. 2012, 'The realities of the past: archaeology, objectorientations, pragmatology', in Fortenberry \& McAtackney 2012, 25-36.

Yazdi, L.P. \& DezhamKhooy, M. 2014, 'The last episode of an Iranian teacher's bag: children's lives as the smaller copies of their parents' in contemporary Iran', Int. J. Hist. Archaeol. 18:3, 513-28.

Zimmerman, L. \& Welch, J. 2010, 'Displaced and Barely visible: Archaeology and the Material Culture of Homelessness', Hist. Archaeol. 45:1, 67-85.

Zimmerman, L., Singleton, C. \& Welch, J. 2010, 'Activism and creating a translational archaeology of homelessness', World Archaeol. 42:3, 44354.

\author{
ABBREVIATIONS \\ CHAT Contemporary and Historical Archaeology \\ in Theory \\ MOLA Museum of London Archaeology \\ PMA Post-Medieval Archaeology \\ SPMA Society for Post-Medieval Archaeology
}

